\title{
Atmospheric water budget over the western Himalayas in a regional climate model
}

\author{
A P DIMRI \\ School of Environmental Sciences, Jawaharlal Nehru University, New Delhi, India. \\ Present address: Hydrospheric Atmospheric Research Center (HyARC), \\ Nagoya University, Nagoya, Japan. \\ email: apdimri@hotmail.com
}

During winter months (December, January, February - DJF), the western Himalayas (WH) receive precipitation from eastward moving extratropical cyclones, called western disturbances (WDs) in Indian parlance. Winter precipitation-moisture convergence-evaporation $(\mathrm{P}-\mathrm{C}-\mathrm{E})$ cycle is analyzed for a period of 22 years (1981-2002: 1980(D)-1981(J, F) to 2001(D)-2002(J, F)) with observed and modelled (RegCM3) climatological estimates over WH. Remarkable model skills have been observed in depicting the hydrological cycle over WH. Although precipitation biases exist, similar spatial precipitation with well marked two maxima is simulated by the model. As season advances, temporal distribution shows higher precipitation in simulation than the observed. However, $\mathrm{P}-\mathrm{C}-\mathrm{E}$ cycle shows similar peaks of moisture convergence and evaporation in daily climatologies though with varying maxima/minima. In the first half of winter, evaporation over WH is mainly driven by ground surface and $2 \mathrm{~m}$ air temperature. Lowest temperatures during mid-winter correspond to lowest evaporation to precipitation ratio as well.

\section{Introduction}

Topography heterogeneity and land use variability are the characteristics of western Himalayas (WH). Western disturbances (WDs), embedded in large scale westerlies (Dimri and Mohanty 2009) are responsible for winter precipitation, mainly snow, in WH. The interplay of topography with WDs determines orographic precipitation over the Himalayan region (Barros and Lettenmaier 1994; Dimri 2004, 2009; Bookhagen and Strecker 2008; Medina et al. 2010). Role of topography (Pielke 2001; Anders et al. 2006) and landuse (Dimri 2009; Fairman et al. 2011; Nair et al. 2011) also influences the water budget over mountainous regions. This winter water balance feeds most of the north Indian rivers with springtime melting of snow (Thayyen and Gergan 2010). Higher winter temperature and lower winter precipitation appear to impact this balance (Dimri and Dash 2011). The changing temperature and precipitation patterns over WH (Dimri and Dash 2011) affect the hydrological regimes (Yang et al. 2002; Thayyen and Gergan 2010) of these river systems.

Studies conducted on hydrological balance have shown impact on precipitation and evaporation with changing surface parameters (Lean and Warrilow 1989; Xu et al. 2009). Precipitation recycling (Eltahir and Bras 1996), water vapour flux field characteristics (Rasmusson 1967) and large scale water balance (Rasmusson 1968) mark the importance of hydrological cycle. Estimates of hydrological components, rates and fresh water run-off are shown by Omstedt et al. (1997) and Elguindi et al. (2009). Role of precipitation - soil moisture feedback with land-atmospheric coupling

Keywords. Moisture feedback; western Himalayas; regional climate. 
(Twafik and Steiner 2010; Zhang et al. 2011), and role of soil moisture in determining regional flood or draught situation (Pal and Eltahir 2003) are studied. With isotopic composition Risi et al. $(2008,2010)$ have shown precipitation and water vapour balance in the tropics and Sahel while Prasanna and Yasunari $(2009,2010)$ have shown summer time water balance over south Asian monsoon region.

A rigorous understanding of hydrological balance over WH is complicated due to the topographical heterogeneity and land use variability which put constraints on observing changes. Few studies have been conducted and limited information is available on water budget over the WH. Further since it is data void region, precise estimation of water budget during winter is also not possible. As a result regional model simulation and its downscaled data output are planned to be used to estimate atmospheric water budget over the WH. Also it is important to assess the relevance of downscale outputs of RCM and their suitability for this study. After verification of regional model sensitivities, role of topography, interplay of topography with WDs in precipitation forming mechanisms, landuse and extremes (Dimri 2012)characteristics of large scale water balance over WH have been examined in this present study. This study aims to facilitate an understanding of hydrometeorological processes - the space time characteristics of seasonal variations of precipitation $(P)$, moisture convergence $(C)$ and evaporation $(E)$.

Section 2 gives a brief description of regional model, experimental design, water budget calculation and data used. While section 3 describes the results and discussion focusing mainly on atmospheric water budget over the WH. Finally salient findings are concluded under section 4 .

\section{Data and methodology}

\subsection{Brief model details}

In this study, an updated regional climate model (RegCM3) is used (Pal et al. 2007). The physical parameterization scheme of Kiehl et al. (1996), the nonlocal boundary scheme of Holtslag et al. (1999), the mass-flux cumulus cloud scheme of Grell (1993), the resolvable-scale cloud and precipitation scheme of Pal et al. (2000), and the land surface processes of Dickinson et al. (1993) are used in the present model simulation configuration. Topographical information for obtaining grids is taken from a 2-min resolution global dataset produced by the United States Geological Survey (USGS). Fine scale fractional land use cover information over different surface types is taken from the Global Land Cover Characterization (GLCC) dataset. Atmospheric fields from the National Centre for Environmental Prediction (NCEP) Reanalysis II (Kanamitsu et al. 2002) are used as initial and lateral boundary conditions. While the National Oceanic and Atmospheric Administration (NOAA) Optimum Interpolation Sea Surface Temperature (OISST) dataset is used for SST over the ocean areas. NCEP reanalysis is conducted at $2.5^{\circ}$ horizontal resolution with 6 hourly time interval, while the OISST dataset is at a $1^{\circ}$ horizontal resolution with a weekly time interval. Brief model details are provided in table 1.

\subsection{Experimental design}

WDs travel as large scale westerlies and approach WH from the west, as a result a larger model domain extending towards west is considered in model simulation. The domain covers area between the Gulf of Aden in west to north India using a Lambert Conformal projection centered over central Asia, with grid cells of $60 \times 60 \mathrm{~km}$ size. Figure 1 (a) presents topography and the entire model domain used in model simulation. In present experimental strategies, simulations were made continuously for 22 years (1981-2002) beginning from 1 September 1980. For first 3 months (1 September 1980-30 November 1980) simulations are not included in the analysis to allow model spin-up. Over the WH region, model spin-up is an important issue in determining the dynamical equilibrium between lateral boundary information and internal model physics and dynamics. Different spin-up time spans are suggested depending on land surface, viz., several decades for ocean model (Kantha and Clayson 2000); one year for land surface (Cosgrove et al. 2003). Giorgi and Mearns (1999) suggested that for normal atmospheric simulations, model spin-up time in days will stabilize the equilibrium. In case of regional climate model including soil module of several meter depths, strict equilibrium occurs only after years of simulations. However, since the most hydrologically active soil region is the rooting zone (order of $1 \mathrm{~m}$ depth or less), for most practical purposes the soil spin-up time can be considered between a season and an year. Keeping latter in view 3 months (a season) preceding to the long term simulation is adopted in this study.

\subsection{Water balance}

The following atmospheric water budget equation is used (Peixoto and Oort 1992; Prasanna and Yasunari 2009, 2010).

$$
\langle\partial W / \partial t\rangle+\langle\nabla \cdot Q\rangle=\langle E-P\rangle
$$


Table 1. Model configurations used in the present study.

\begin{tabular}{ll}
\hline No. of horizontal grid points: & iy $=51$ (along y-direction) \\
& $\mathrm{j} \mathrm{x}=61$ (along x-direction) \\
No. of vertical levels & $\mathrm{Kz}=23$ \\
Distance between grid points & $\mathrm{ds}=60 \mathrm{~km}$ \\
Centre of latitude & $31^{\circ} \mathrm{N}$ \\
Centre of longitude & $70^{\circ} \mathrm{E}$ \\
Horizontal grid scheme & Arakawa-Lamb B grid staggering \\
Time integration scheme & Split explicit \\
Surface parameters & BATS1E \\
Map-projection & Lambert conformal \\
Sea surface temp. & OISST \\
Data type & NNRP2 \\
Model physics & \\
Cumulus scheme & Grell \\
Grell scheme convective closure scheme & Fristch and chappell \\
Lateral boundary condition & Relaxation(exponential) \\
Planetary boundary layer scheme & Holtslag \\
Large scale precipitation scheme & SUBEX \\
Ocean flux parameterization scheme & Zeng \\
Pressure gradient scheme & Normal way \\
Lake model & No \\
Tracer/chemistry model & No \\
\hline
\end{tabular}

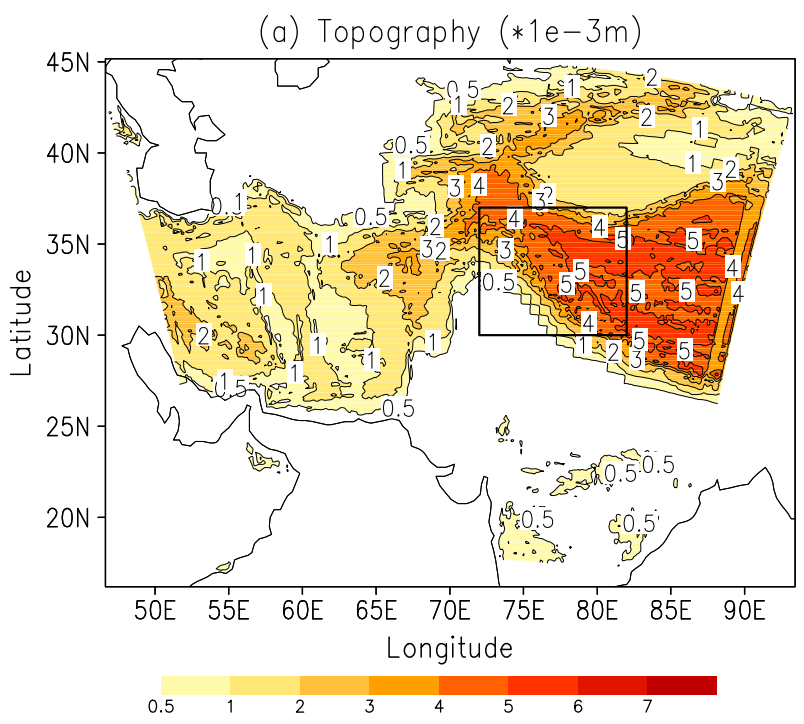

Figure 1. (a) Model domain and topography (*1e-3m) used in the present study. Area $\left(30^{\circ} \mathrm{N} 72^{\circ} \mathrm{E}-37^{\circ} \mathrm{N} 82^{\circ} \mathrm{E}\right)$ marked with box is chosen discussion in the study.

where, $P$ is the precipitation, $E$ is the evaporation, $W$ is the precipitable water content, $Q$ is vertically integrated moisture flux vector, $\nabla \cdot Q$ is the divergence and angled brackets denote the area average.

On a longer time scale, like monthly or seasonal and under near equilibrium conditions, the time change of local available precipitable water content is negligible when compared to variations of large scale convergence and evaporation (Oki et al. 1995; Trenberth and Guillemot 1999).

$$
\left\langle\frac{\partial W}{\partial t}\right\rangle \approx 0
$$

We can approximate

$$
P \sim C+E
$$

where $C=-\langle\nabla \cdot Q\rangle$

Vertically integrated moisture flux vector is given by (Hagemann et al. 2005; Trenberth et al. 2005; Graversen et al. 2007)

$$
Q=\frac{1}{g} \int_{P_{t}}^{P_{s}} q v d p
$$

where $q$ is the specific humidity, $v$ is the horizontal wind vector, $P_{s}$ is the pressure at surface level and $P_{t}$ is the pressure at the top of the atmosphere, $g$ is the gravitational acceleration. Vertical integration is performed from the ground (surface pressure level) to $300 \mathrm{hPa}$ for all the standard atmospheric pressure levels. We can neglect pressure levels above $300 \mathrm{hPa}$, as specific humidity above this level is negligible. The moisture flux divergence that is the second term in the left hand side of the equation (1) and the vertically integrated moisture fluxes are computed using the linear grid. 


\subsection{Data}

The moisture convergence data is computed every six hours from six hourly upper-level winds $(u, v)$, specific humidity $(q)$, geo-potential height $(z)$, surface winds $\left(u_{S}, v_{S}\right)$, surface-level specific humidity $\left(q_{S}\right)$ and sea level pressure $\left(P_{s}\right)$ obtained from the Japanese 25-year Reanalysis (JRA-25) dataset (Onogi et al. 2007) and RegCM3 model simulations. For observation, the residual evaporation dataset $(E)$ is obtained from the observed $0.25^{\circ}$ resolution gridded precipitation dataset $(P)$ for Asia (APHRODITE) (Yatagai et al. 2009) and computed moisture convergence dataset $(C)$ from JRA25 reanalysis, since the $P$ from APHRODITE is more reliable over WH region. Similarly, for model, the residual evaporation dataset $(E)$ is obtained between model simulated precipitation dataset $(P)$ and computed moisture convergence dataset $(C)$ from model result. Water balance during the period of 22 years (1981-2002) is computed. Here it is important to justify usages of independent JRA reanalysis over forced reanalysis. After validating model sensitivity, land use and role of topography with corresponding analysis (Dimri 2012), model results with independent JRA analysis is used because it provides finer horizontal and vertical resolution and also, provides snow depth. Also, for water balance analysis APHRODITE precipitation is used to compute convergence. With these assumptions JRA reanalysis is used.

\section{Results and discussion}

The following paragraphs present the analysis of winter $\mathrm{P}-\mathrm{C}-\mathrm{E}$ cycle over $\mathrm{WH}$, the observed and modelled winter precipitation climatology, followed by daily climatologies and $\mathrm{P}-\mathrm{C}-\mathrm{E}$ cycles.

\subsection{Climatology}

Winter precipitation over $\mathrm{WH}$ is important as it is the major source of water for north Indian rivers. Figure 2(a and b) shows a 22-year, 3-month (DJF) seasonal average observed (APHRODITE) and modelled precipitation climatology respectively. Observation shown mean seasonal winter precipitation is generally wet over $\mathrm{WH}$ with center of maxima lying over the Hindukush and Indo-Pak Himalayan regions. The RegCM3 simulation is able to capture the basic structure of precipitation climatology and is in good agreement over Hindukush and Indo-Pak Himalaya. The model overestimates seasonal precipitation by $\sim 2-3 \mathrm{~mm} / \mathrm{d}$ showing a wet bias particularly over higher mountainous peaks. This reason could be attributed to the role of topographically induced precipitation along the Himalayan region. In general, the spatial patterns of precipitation are well produced, with correlation coefficients of 0.77 with APHRODITE (significant at $95 \%$ confidence interval). The spatial correlation coefficients are calculated after the observations are aggregated onto model grid, including all points in the interior domain. To assess spatial variability further, variance to precipitation ratio (in percentage) over the $\mathrm{WH}$ is presented for observed and modelled in figure 2(c and d) respectively. The observations exhibit two prominent maxima - one over the Indo-Pak region and another over Indo-Nepal region - elongated along the Himalayan topography. However, corresponding modelled variance to precipitation ratio could not explicitly provide exact ratio distribution and also was in lower order than the observation. Due to higher precipitation, bias model projects lower variability over the region. Only resemblance model simulations provide the spread of variance to precipitation ratio along the Himalayan topography (Dimri 2012). During winter, most of the precipitation accumulated over the $\mathrm{WH}$ is in the form of solid precipitation (snow), as a result, threshold corresponding to this phase change - liquid to solid or vice versa - needs to be better understood to explain the variance. RegCM3 model has capability to explain this variance up to a certain extent and hence model simulated snow depth is compared with corresponding observation reanalysis field (JRA). Spatial distribution of observed and modelled snow depth climatology is analyzed and presented in figure 2(e and f) respectively. Model could simulate spatial distribution well, as seen in observation. While region of highest snow depth could be simulated by model though with more spatial distribution. It is important to note that over the WH during winter, accumulated fresh snow provides higher albedo and decrease in atmospheric temperatures and clear skies after bad weather. These (snow-albedo feedback and decreasing air temperature) situations are important for understanding of $\mathrm{P}-\mathrm{C}-\mathrm{E}$ balance during winter. Based on 22-year (1980-2002) daily winter precipitation climatology, higher spatial precipitation and variability is seen over regions $\left(30^{\circ} \mathrm{N} 72^{\circ} \mathrm{E}-37^{\circ} \mathrm{N} 82^{\circ} \mathrm{E}\right)$, as shown in figure 1(a). Also, this region receives highest seasonal precipitation (figure not presented). Hereafter this region is considered for further study of $\mathrm{P}-\mathrm{C}-\mathrm{E}$ cycle and referred as the $\mathrm{WH}$.

\subsection{Intraseasonal variation}

The 22-year daily averaged, observed (APHRODITE) and model precipitation climatology, anomaly, mean and \pm 1 standard deviation 
(a) Observed prec clim $(\mathrm{mm} / \mathrm{d})$

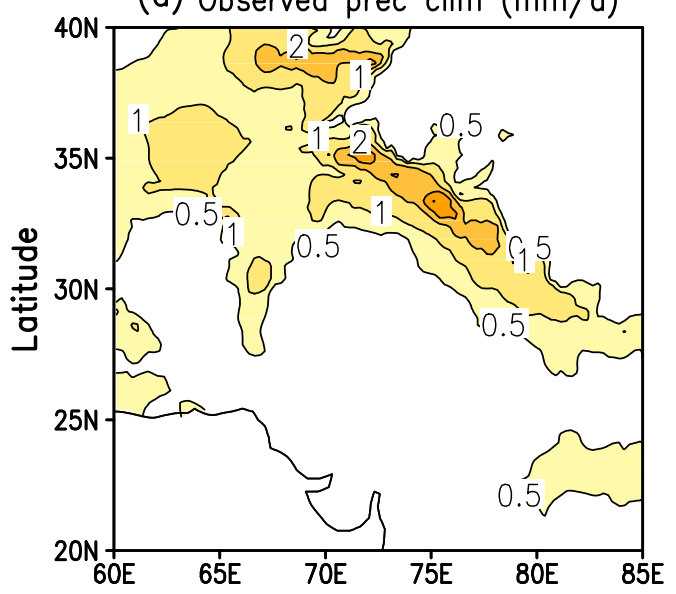

(c) Observed variance/prec ratio

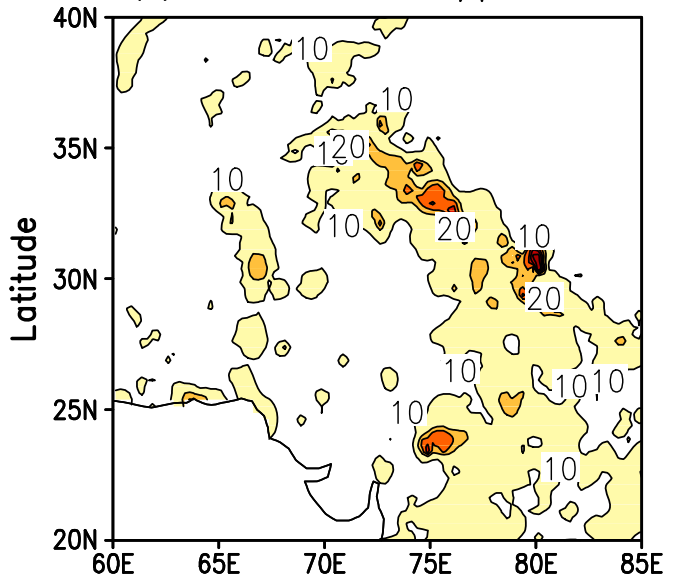

(e) Observed Snowdepth $(\mathrm{cm})$

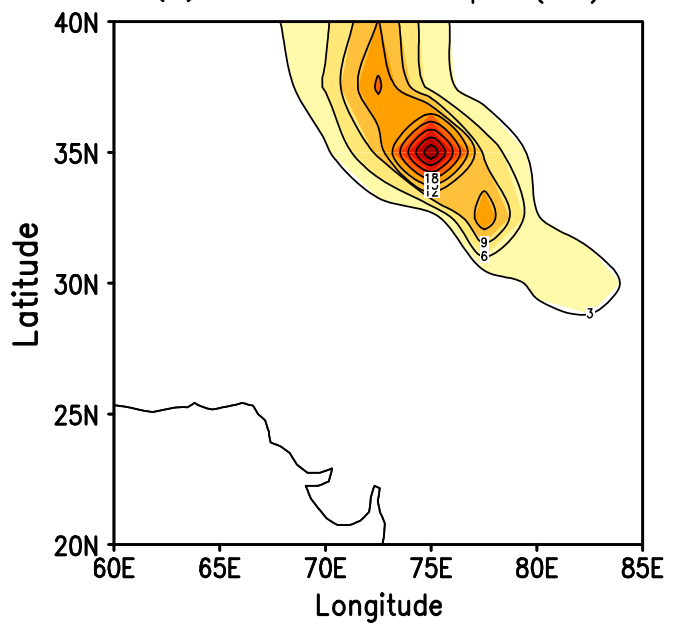

(b) Modeled prec clim $(\mathrm{mm} / \mathrm{d})$

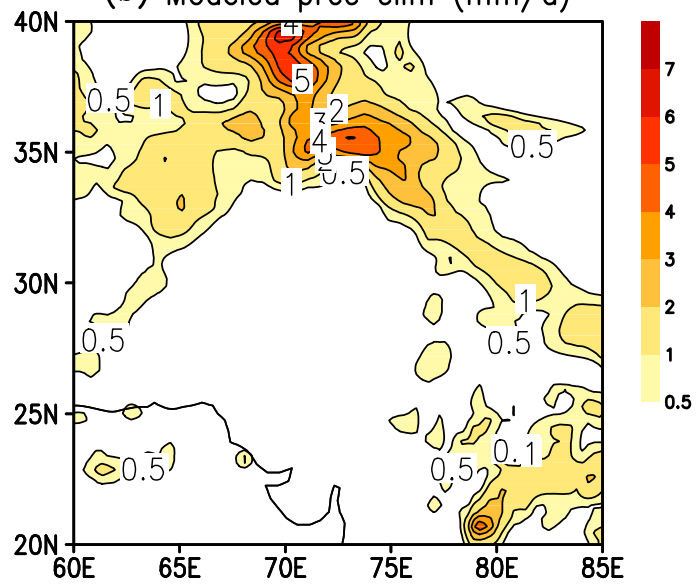

(d) Modeled variance/prec ratio

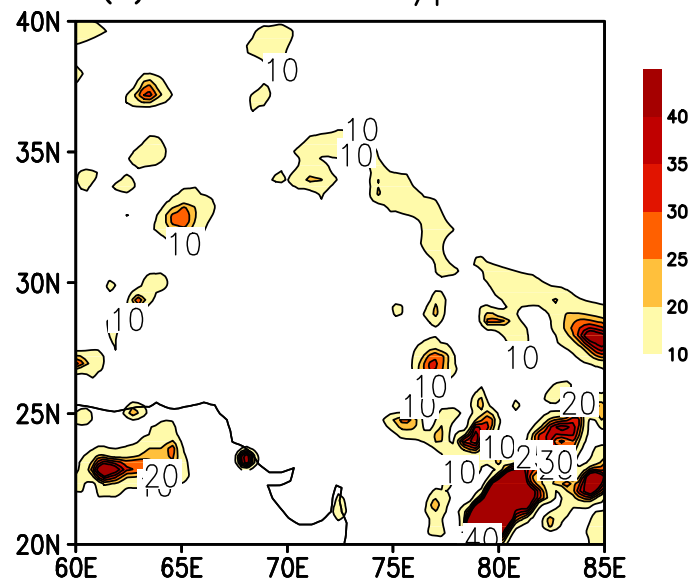

(f) Modeled Snowdepth $(\mathrm{cm})$

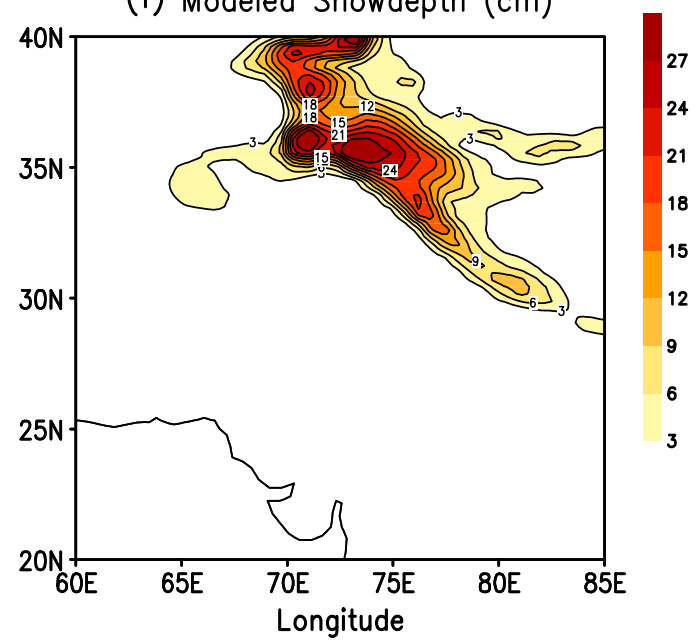

Figure 2. 3-month (DJF) average precipitation climatology (mm/d) in (a) observed (APHRODITE) and (b) modelled (RegCM3); 3-month (DJF) average variance to precipitation ratio in (c) observed (APHRODITE) and (d) modelled (RegCM3); 3-month (DJF) average snow depth climatology (cm) in (e) observed (JRA-25) and (f) modelled (RegCM3).

(SD) averaged over the WH is presented in figure 3(a and b) respectively. Model has wet bias and hence shows higher mean precipitation of $1.9 \mathrm{~mm} / \mathrm{d} \quad(\mathrm{SD}=0.6 \mathrm{~mm} / \mathrm{d})$ than observed of $1.1 \mathrm{~mm} / \mathrm{d} \quad(\mathrm{SD}=0.4 \mathrm{~mm} / \mathrm{d})$. Similar temporal daily distribution of precipitation is modelled. As season advances, higher daily precipitation is seen through December to February. Model could also simulate such precipitation distribution. Intraseasonal variability in observed and modelled 
(a) Daily 22yr (1981-02) average Prec $(\mathrm{mm} / \mathrm{d})$ : Observation

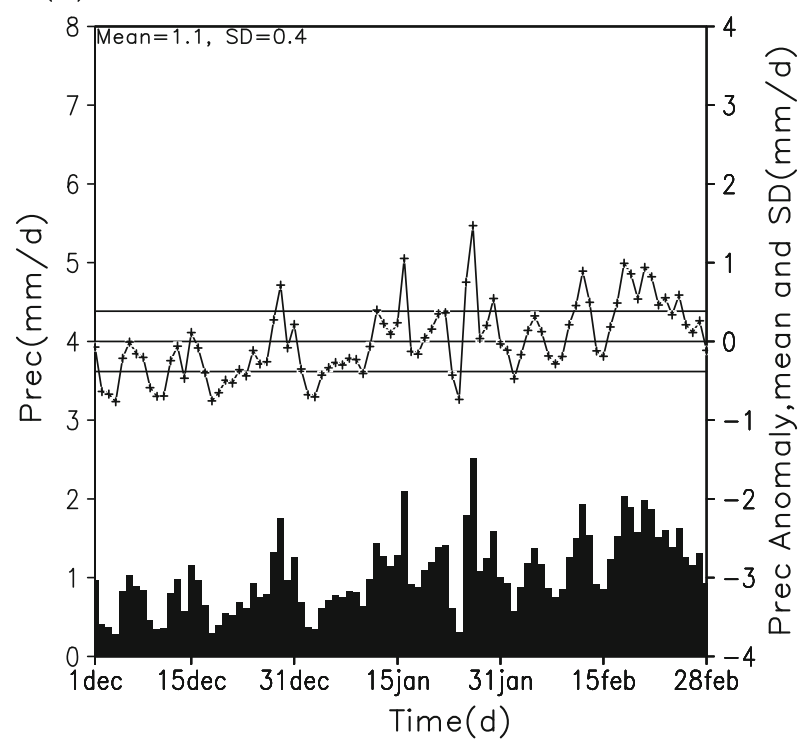

(b) Daily 22yr (1981-02) average Prec $(\mathrm{mm} / \mathrm{d})$ : Model

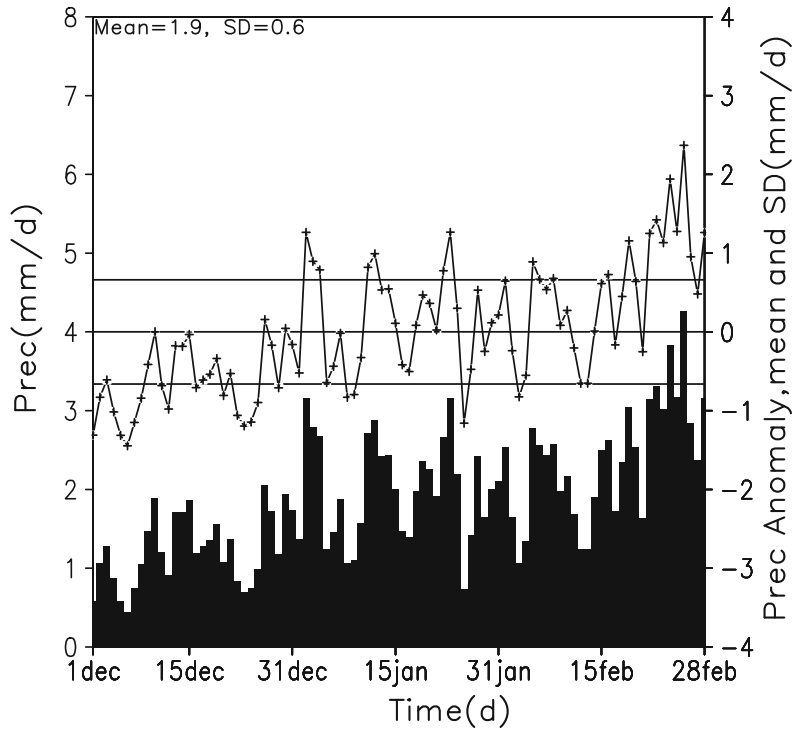

Figure 3. 22-year area $\left(30^{\circ} \mathrm{N} 72^{\circ} \mathrm{E}-37^{\circ} \mathrm{N} 82^{\circ} \mathrm{E}\right)$ averaged daily 3-month (DJF) precipitation climatology $(\mathrm{mm} / \mathrm{d})(\mathrm{left}$ side); corresponding precipitation anomaly, mean, and SD $(\mathrm{mm} / \mathrm{d})$ (right side) for (a) observed (APHRODITE) and (b) modelled (RegCM3).

precipitation corresponds to the occurrence/passage of WD. There are higher precipitation days corresponding to the average life cycle of 2-3 days of WDs over the WH (Mohanty et al. 1998). There are days when higher precipitation is observed and which are simulated by this model. It is important to mention that even though the model has wet bias it has the ability to produce extreme, excess and deficit precipitation days. Precipitation anomaly distribution shows similar number of days above (below) +1SD (-1SD) in observed and model result. Though there are differences in snow depth, regional model shows a very similar temporal evolution of snow depth in 22 years simulation. This could be due to synoptic weather systems, WDs, while travelling over the WH come into interaction with the various mountain ranges in a cascading manner (from Pir Panjal range $\rightarrow$ Great Himalaya $\rightarrow$ Zanskar $\rightarrow$ Ladhak $\rightarrow$ Karakoram range at last). Such ridge-valley geographical situations will provide orographic forcing to define precipitation mechanism over the WH. During this sequence, moisture available to the WDs will be shaded due to orographic forcing over the first range and lesser moisture will be left for following ranges. This hypothesis in a way suggests that more refined and seemingly more realistic precipitation and/or snow patterns need enhanced topographic representation, which otherwise will be difficult to account. There is a need of denser network of stations. Though the model has wet bias over the WH, it has the ability to reproduce intraseasonal variability over the WH with reasonable accuracy. This affirms that downscaled outputs from RegCM3 can be used to estimate important $\mathrm{P}-\mathrm{C}-\mathrm{E}$ cycle and/or water budget over the $\mathrm{WH}$ - which is discussed in the following subsection.

\subsection{Precipitation-moisture convergence- evaporation cycle}

Spatial distribution of observed (JRA-25) and model computed vertical integrated moisture divergence and transport is presented in figure 4(a and b) respectively. Spatial pattern shows similar elongated convergence (divergence) zone over and along the Himalayan (foothill of the Himalayan) region in observed and modelled field. Quantitatively, model simulated fluxes with lesser order. These, similar elongated cellular structures of convergence (divergence) found over and along the Himalayas (foothill) are highly influenced by local topographic variabilities and landuse changes. Strictly, such simulations are dependent on how surface fluxes and their feedback are represented in model physics. Detailed scrutiny shows that over the Himalayan foothills $\left(32^{\circ} \mathrm{N} 77^{\circ} \mathrm{E}-27^{\circ} \mathrm{N} 82^{\circ} \mathrm{E}\right)$, model simulates few of the cellular structures of divergence. Alternate zones of convergence and divergence, as seen in observation though modelled, have lesser order and their cellular structured patterns are reproduced corresponding to the observed field. Dominating effect of local orography in defining convergence zone is observed. The observed fluxes show much higher vertical integrated moisture flux over the Himalayan region. This higher flux, though not seen in the model results, is probably due to large scale flow than 


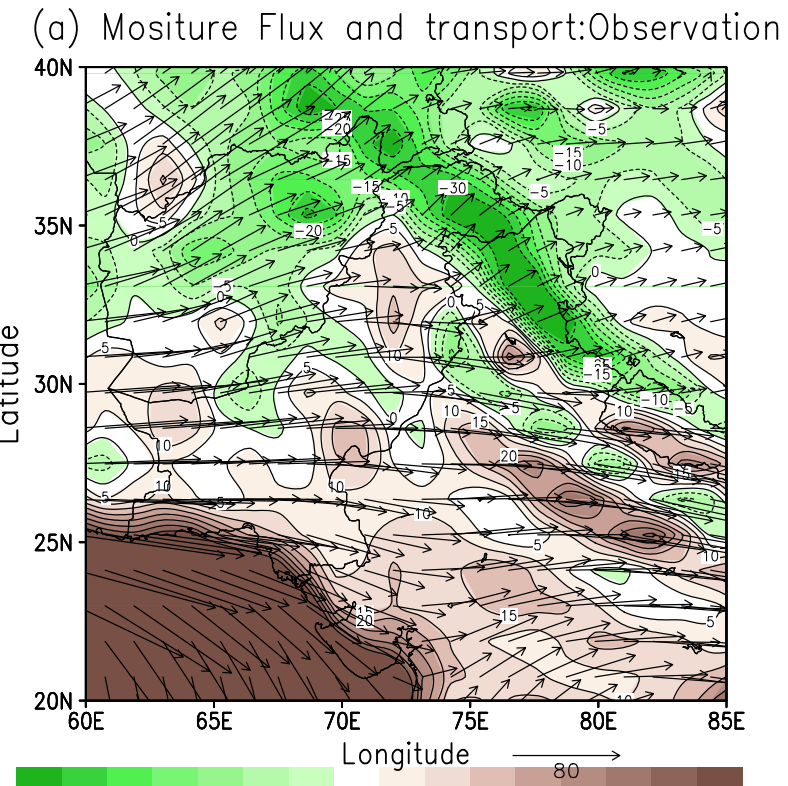

$-30-25-20-15-10-5 \quad 0 \quad 5 \quad 10 \quad 15 \quad 20 \quad 25 \quad 30 \quad 35 \quad 40$

(b) Moisture Flux and transport:Model

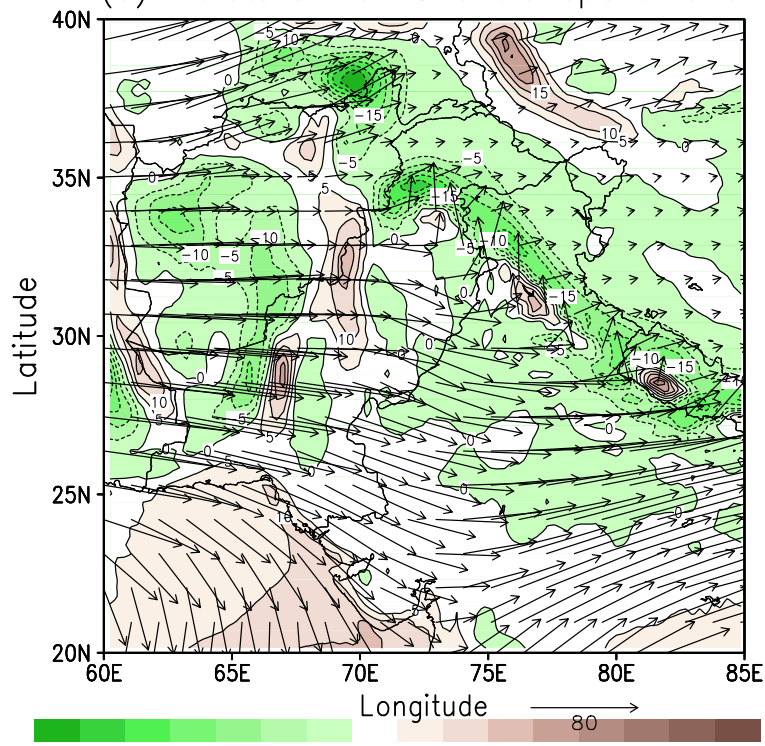

$-30-25-20-15-10-5 \quad 0 \quad 5 \quad 10 \quad 15 \quad 20 \quad 25 \quad 30 \quad 35 \quad 40$

Figure 4. 22-year averaged vertical integrated moisture flux (vector: $\mathrm{kg} / \mathrm{m} / \mathrm{s}$ ) and divergence (shaded:mm/d) over the Himalayan region (a) observed (JRA-25) and (b) modelled (RegCM3).

the model domain simulations. However, convergence in upslope is mainly due to rise of air, which will shed condensed moisture along the upslope (Yasunari 1976; Singh et al. 1995). Also, over the Himalayan region, precipitation occurrence has certain altitudinal limits based on orographic forcings (Burbank et al. 2003; Bookhagen et al. 2005; Bookhagen and Burbank 2006). Further, interaction of the large-scale flow with suitable mountain geometry gives significant precipitation
(Lang and Barros 2004; Medina et al. 2010). In case of moisture transport over the regions, model shows more curvature flow over north Indian region than the observed. Such modelled flow produces more convergence over Indo-Gangetic plain, which is not seen in corresponding observation. Here, one point needs to be emphasized that model results are downscaled to a finer resolution than the corresponding observation. Sometimes it may happen that while flow approaching the Himalayan orography will have distinct forcing, which could only be simulated with certain constraints. In composite, transport fluxes are represented within order and their direction is also simulated corresponding with observation and with convergence fields. Further observed and modelled 22 years averaged daily $\mathrm{P}-\mathrm{C}-\mathrm{E}$ cycle averaged over regions of interest is shown in figure 5 (a and b) respectively. Comparison shows similar as well as interesting patterns in observation and model. Most of the contribution to winter precipitation is from large scale convergence rather than the surface evaporation. Whenever there is higher convergence, higher precipitation is shown in observation and model. Apart from this, days with climatological precipitation maxima and minima too, match well. It is found that whenever convergence peaks, a precipitation maximum occurs too. Moreover, temporal distribution shows a periodic $2-3$ days association with convergence peak and precipitation maximum. These features can be attributed and associated with life cycle of WDs occurring during winter. Based on such distribution, it also can be deduced how frequently WDs occur over the Himalayan region. Further, as season advances, interesting similar increase in convergence and precipitation is seen, whereas evaporation fields almost remain the same. However, there are days when evaporation is higher in both, model and corresponding observation. Evaporation is the main attribute of surface flux, to investigate it, corresponding role of $2 \mathrm{~m}$ air and surface temperature is analyzed. Difference between 22-year daily averaged $2 \mathrm{~m}$ air and surface temperature and evaporation averaged over region of interest is presented in figure 6(a and b) for observation and model respectively. In latter half of winter, higher positive temperature differences show higher evaporation over the region. As season advances, $2 \mathrm{~m}$ warming leads to higher evaporation, which witnessed in both observation and model output as well. Peaks of higher difference match with higher evaporation of 0.57 and 0.62 correlation coefficient (with $95 \%$ significance) for observation and model respectively. Such findings are important in hydrological and glacier basin studies to estimate corresponding melt during spring/melt period. Inference from downscaled 
model simulation can provide important rationale/ estimations for projects like dam building, reservoir construction, flood management, etc., in data sparse mountainous region. To analyze further, role of $2 \mathrm{~m}$ air temperature, figure 7 depicts changes in evaporation to precipitation ratio with $2 \mathrm{~m}$ air temperature in observation and model. Pentad mean of

(a) 22yr (1981-02) Daily average $P / C / E(m m / d): O b s e r v a t i o n$

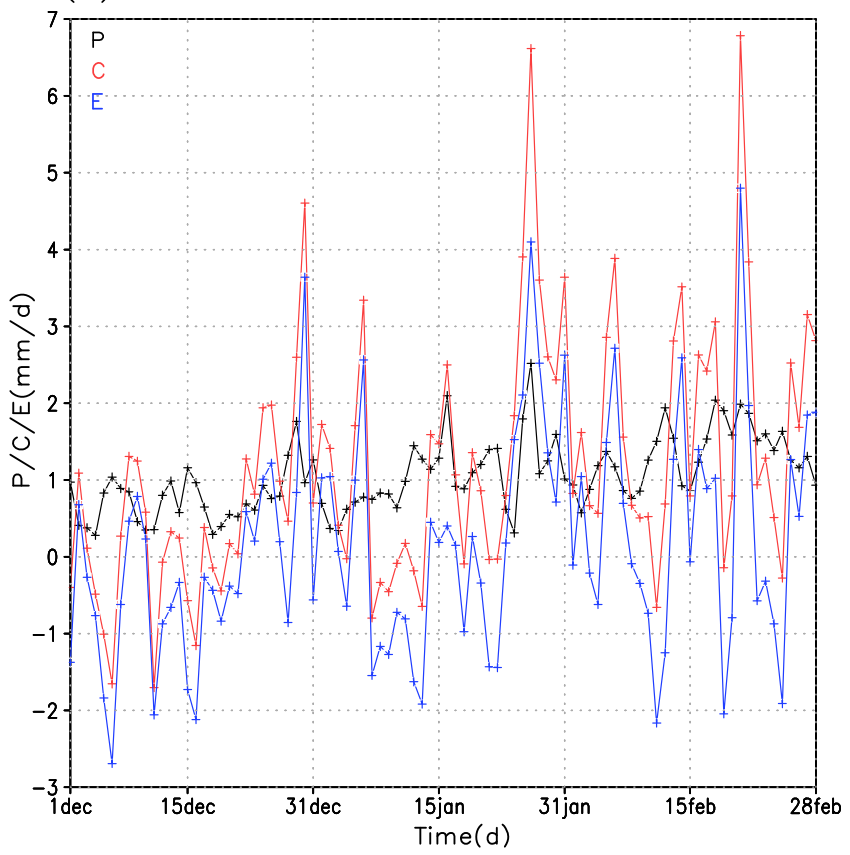

(b) 22yr (1981-02) Daily average $P / C / E(\mathrm{~mm} / \mathrm{d})$ :Model

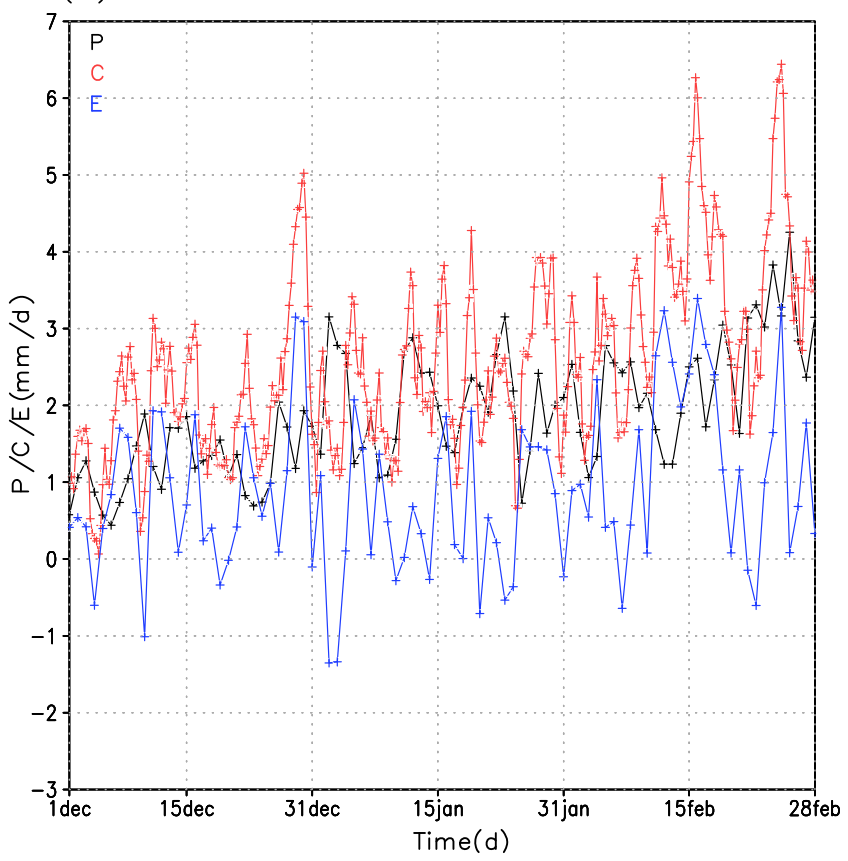

Figure 5. 22-year area $\left(30^{\circ} \mathrm{N} 72^{\circ} \mathrm{E}-37^{\circ} \mathrm{N} 82^{\circ} \mathrm{E}\right)$ averaged daily 3-month (DJF) P-C-E climatology ( $\mathrm{mm} / \mathrm{d})$ for (a) observed (APHRODITE and JRA-25) and (b) modelled (RegCM3). (a) Daily 22yr (1981-02) average : Observation

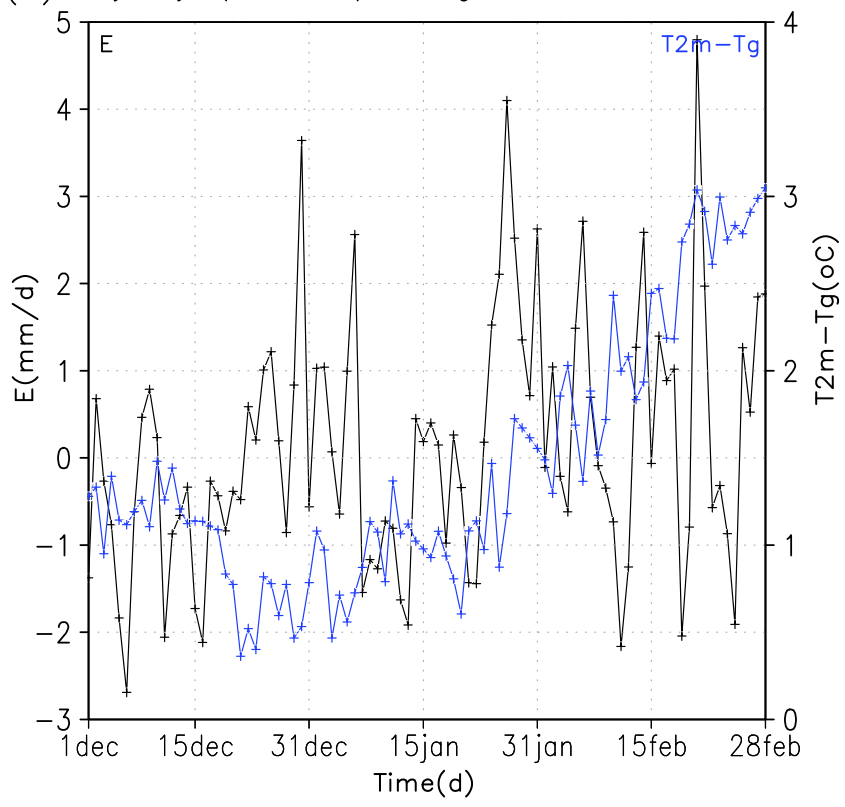

(b) Daily 22yr (1981-02) average : Model

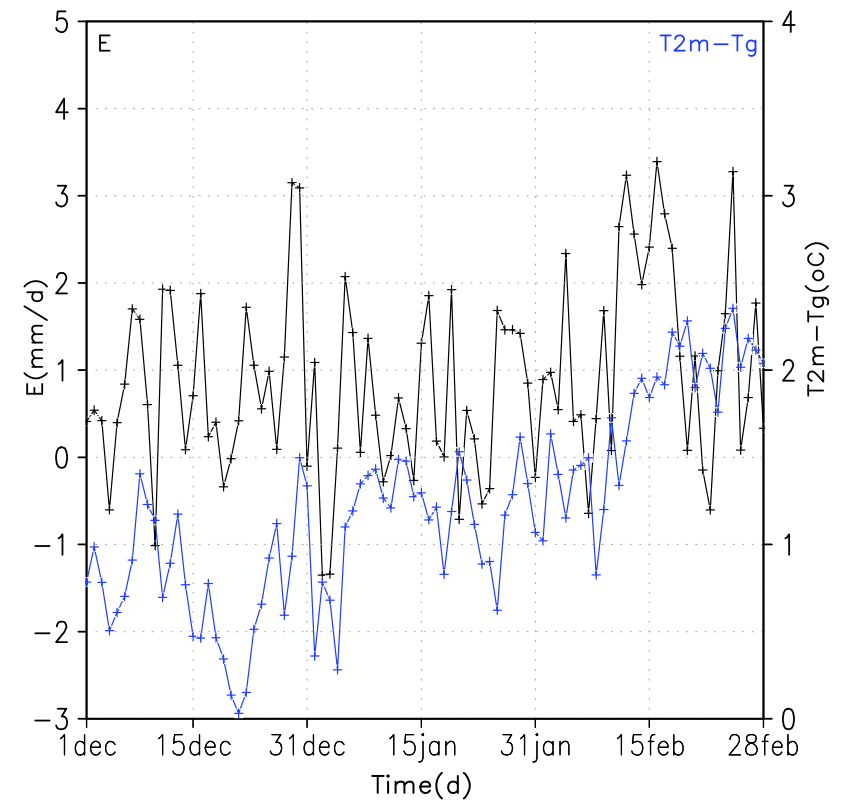

Figure 6. 22-year area $\left(30^{\circ} \mathrm{N} 72^{\circ} \mathrm{E}-37^{\circ} \mathrm{N} 82^{\circ} \mathrm{E}\right)$ averaged daily 3 -month (DJF) $\mathrm{E}(\mathrm{mm} / \mathrm{d})$ and difference between $2 \mathrm{~m}$ air temperature $(\mathrm{T} 2 \mathrm{~m})$ and ground surface $(T \mathrm{~g})$ temperature $(\mathrm{T} 2 \mathrm{~m}-\mathrm{Tg})\left({ }^{\circ} \mathrm{C}\right)$ climatology for (a) observed (APHRODITE and JRA-25) and (b) modelled (RegCM3).

evaporation to precipitation ratio and $2 \mathrm{~m}$ air temperature in observation and model over the $\mathrm{WH}$ is presented in figure 7 (a). It shows that though there is cold bias in model simulations, similar variations in winter temperatures as seen in observations are noticed. Similar temporal variability in temperature field is seen. During peak lowest temperature regime (mid winter) evaporation to precipitation ratio is lowest in observed and model. As $2 \mathrm{~m}$ 
(a)
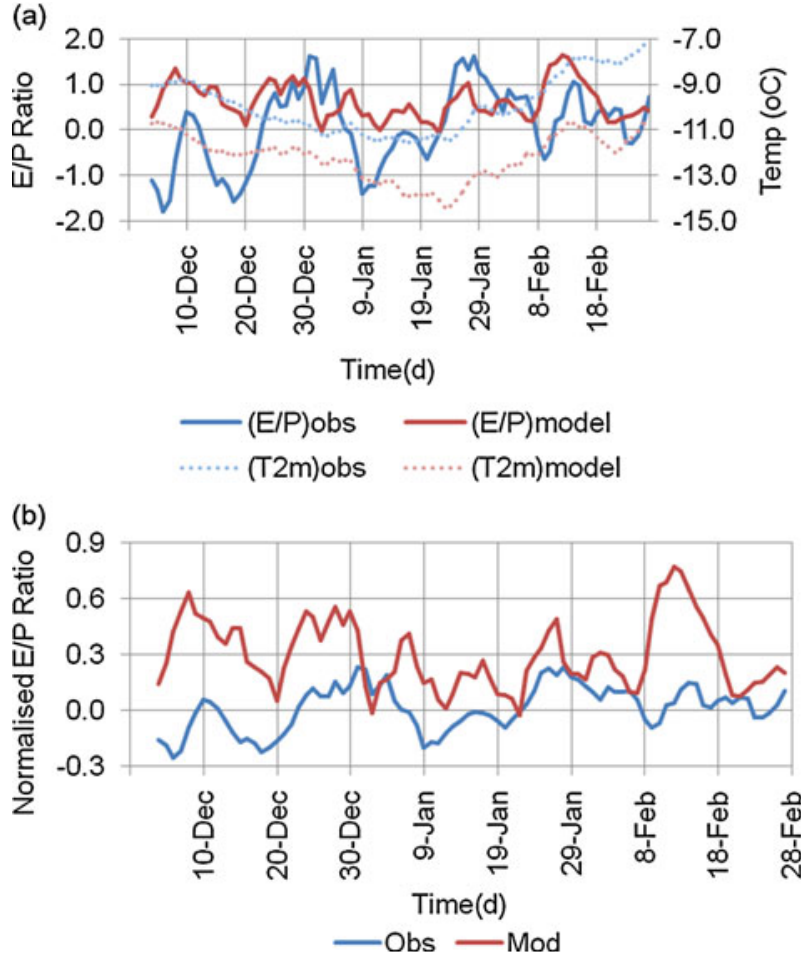

Figure 7. (a) 22 -year area $\left(30^{\circ} \mathrm{N} 72^{\circ} \mathrm{E}-37^{\circ} \mathrm{N} 82^{\circ} \mathrm{E}\right)$ averaged daily pentad for 3 -month (DJF) evaporation to precipitation ratio $(\mathrm{E} / \mathrm{P})$ and $2 \mathrm{~m}$ air temperature $(\mathrm{T} 2 \mathrm{~m})\left({ }^{\circ} \mathrm{C}\right)$ as observed and modelled and (b) pentad mean of climatological normalized evaporation to precipitation ratio.

air temperature increases, evaporation to precipitation ratio also increases. Further, pentad mean of climatological normalized evaporation to precipitation ratio, shows similar increase and decrease (figure $7 \mathrm{~b}$ ). Temporal variation in wet and dry phases is well simulated in model fields. It suggests that model's ability to reproduce estimated $\mathrm{P}-\mathrm{C}-\mathrm{E}$ cycle over the WH.

\section{Summary and conclusions}

Present work illustrates role of precipitationmoisture convergence-evaporation cycle over the WH during winter. Due to topographic heterogeneity and landuse variability, precipitation forming processes are complex. The present study attempts to assess the contribution of large scale flow and/or surface evaporation to precipitation with observation and regional model simulations. Through this study, it is observed that downscaled model outputs can provide a good estimation for atmospheric water budget over data sparse western Himalayan region.

Similar intraseasonal variations are seen by model results over the WH. Temporal variations in accumulated precipitation field correspond to life cycle of WDs. This climatological variability is explained in model precipitation climatology as well. Moisture convergence with lower order but with similar direction of moisture transport is simulated by regional model over the WH. Further, over the $\mathrm{WH}$, during winter, $\mathrm{P}-\mathrm{C}-\mathrm{E}$ cycle is controlled by $2 \mathrm{~m}$ air and surface temperature gradient which are seen though with some cold bias in model simulation. As winter advances, increase in $2 \mathrm{~m}$ air temperature increases the evaporation rate. Normalized evaporation to precipitation ratio estimates show similar wet and dry phases in winter time.

Estimation of $\mathrm{P}-\mathrm{C}-\mathrm{E}$ cycle as produced by model simulation is important in defining water budget over the WH. Such knowledge is of utmost importance for regional development such as water, agriculture, tourism, flood management, etc.

\section{Acknowledgements}

The author acknowledges the ESP, ICTP, Italy; CRU, UK; NCEP/NCAR, US and SASE, Chandigarh, India for using their data sources. Author thanks Dr D Niyogi and three anonymous reviewers for their comments in preparing the manuscript. Author also acknowledges Ms R Bangia for editing the manuscript.

\section{References}

Anders A M, Roe G H, Hallet B, Montgomery D R, Finnegan N J and Putkonen J 2006 Spatial patterns of precipitation and topography in the Himalayas, In: Tectonics, Climate, and Landscape Evolution (eds) Willett S D, Hovius N, Brandon M T and Fisher D M, Geol. Soc. Am. Spec. Paper 398, Penrose Conference Series, pp. 39-53.

Barros A P and Lettenmaier D P 1994 Dynamic modeling of orographically induced precipitation; Rev. Geophys. 32 $265-284$.

Bookhagen B and Burbank D W 2006 Topography, relief and TRMM-derived rainfall variation along the Himalaya; Geophys. Res. Lett. 33 1-5.

Bookhagen B and Strecker M R 2008 Orographic barriers, high resolution TRMM rainfall, and relief variations along the eastern Andes; Geophys. Res. Lett. 35 1-6.

Bookhagen B, Thiede R C and Strecker M R 2005 Abnormal monsoon years and their control on erosion and sediment flux in high, arid northwest Himalaya; Earth Planet. Sci. Lett. 231 131-146.

Burbank D W, Blythe A E, Putkonen J, Pratt-Sitaula B, Gabet E, Oskin M, Barros A and Ojha T P 2003 Decoupling of erosion and precipitation in the Himalayas; Nature 426 652-655.

Cosgrove B A and Co-authors 2003 Land surface model spin up in the North American land data assimilation system (NLDAS); J. Geophys. Res. 108(8845) 19p.

Dickinson R E, Henderson-Sellers A and Kennedy P J 1993 Biosphere-atmosphere transfer scheme (BATS) version 1e as coupled to the NCAR Community Climate Model, NCAR Tech. Note NCAR/TN-387+STR, 72p. 
Dimri A P 2004 Impact of horizontal model resolution and orography on the simulation of a western disturbance and its associated precipitation; Meteorol. Appl. 11 $115-127$.

Dimri A P 2009 Impact of subgrid scale scheme on topography and landuse for better regional scale simulation of meteorological variables over the Western Himalayas; Clim. Dyn. 32 565-574.

Dimri A P 2012 Wintertime land surface characteristics in climatic simulations over the western Himalayas; J. Earth Syst. Sci. 121(2) 329-344.

Dimri A P and Dash S K 2011 Wintertime climatic trends in the western Himalayas; Clim. Change 111(3-4) 775-800, doi: $10.1007 /$ s10584-011-0201-y.

Dimri A P and Mohanty U C 2009 Simulation of mesoscale features associated with intense western disturbances over western Himalayas; Meteorol. Appl. 16 289-308.

Elguindi N S, Somot M Deque and Ludwig W 2009 Climate change evolution of the hydrological balance of the Mediterranean, Black and Caspian Seas: Impact of climate model resolution; Clim. Dyn. 36 205-228.

Eltahir E A B and Bras R L 1996 Precipitation recycling; Rev. Geophys. 34 367-378.

Fairman J G Jr, Nair U S, Christopher S A and Molg T 2011 Land use change impacts on regional climate over Kilimanjaro; J. Geophys. Res. 116, doi: 10.1029/ 2010JD014712.

Giorgi F and Mearns L O 1999 Introduction to special section: Regional climate modeling revisited; J. Geophys. Res. 104 6335-6352.

Graversen R G, Kallen E, Tjernstrom M and Kornich H 2007 Atmospheric mass-transport inconsistencies in ERA-40 analysis; Quart. J. Roy. Meteor. Soc. 133 673-680.

Grell G A 1993 Prognostic evaluation of assumptions used by cumulus parameterization; Mon. Weather Rev. 121 764-787.

Hagemann S, Arpe K and Bengtsson L 2005 Validation of the hydrological cycle of ERA-40, ERA-40 Project Report Series, 24, 42p.

Holtslag A A M, de Bruijn E I F and Pan H L 1999 A high resolution air mass transformation model for short-range weather forecasting; Mon. Weather Rev. 118 1561-1575.

Kanamitsu M, Ebisuzaki W, Woolen J, Yang S-K, Hnilo J J, Fiorino M and Potter G L 2002 NCEP-DOE AMIP-II reanalysis (R-2); Bull. Am. Meteor. Soc. 83 1631-1643.

Kantha L H and Clayson C A 2000 Numerical models of oceans and oceanic processes; Acedemic Press, 940p.

Kiehl J T, Hack J J, Bonn G B, Boville B A, Briegleb B P, Williamson D L and Rasch P J 1996 Description of the NCAR Community Climate Model (CCM3), NCAR Tech. Note NCAR/TN-420+STR, 152p.

Lang T J and Barros A P 2004 Winter storms in the central Himalayas; J. Meteor. Soc. Japan 82 829-844.

Lean J and Warrilow D A 1989 Simulation of the regional climatic impact of Amazon deforestation; Nature 342 411-413.

Medina S, Houze R A Jr, Kumar A and Niyogi D 2010 Summer monsoon convection in the himalayan region: Terrain and land cover effects; Quart. J. Roy. Meteor. Soc. 136 593-616.

Mohanty U C, Madan O P, Rao P L S and Raju P V S 1998 Meteorological fields associated with western disturbances in relation to glacier basins of western Himalayas during winter season; Center for Atmospheric Sciences, Indian Institute of Technology, New Delhi, Technical Report.
Nair U S, Wu Y, Kala J, Lyons T J, Pielke R A Sr and Hacker J M 2011 The role of landuse change on the development and evolution of the west coast trough, convective clouds, and precipitation in southwest Australia; J. Geophys. Res. 116, doi: 10.1029/2010JD014950.

Oki T, Musiake K, Matsuyama H and Masuda K 1995 Global atmospheric water balance and run off from large river basins; Hydrol. Processes 9 655-678.

Omstedt A, Meuller L and Nyberg L 1997 Interanual, seasonal and regional variations of precipitation and evaporation over Baltic Sea; Ambio 26 484-492.

Onogi K, Tsusui J, Koide H, Sakamoto M, Kobayashi S, Hatsushika H, Matsumoto T, Yamazaki N, Kamahori H, Takahashi K, Kodokura S, Wada K, Kato K, Oyama R, Ose T, Mannoji N and Taira R 2007 The JTA-25 reanalysis; J. Meteor. Soc. Japan 85 369-432.

Pal J S and Eltahir E A B 2003 A feedback mechanism between soil moisture distribution and storm tracks; Quart. J. Roy. Meteor. Soc. 129 2279-2297.

Pal J S and Coauthors 2007 The ICTP RegCM3 and RegCNET: Regional climate modeling for the developing world; Bull. Am. Meteor. Soc. 88 1395-1409.

Pal J S, Small E E and Eltahir E A B 2000 Simulation of regional-scale water and energy budgets: Representation of subgrid cloud and precipitation processes within RegCM; J. Geophys. Res. 105 29,576-29,594.

Peixoto J P and Oort A H 1992 Physics of Climate; Am. Inst. Phys., 520p.

Pielke R A Sr 2001 Influence of the spatial distribution of vegetation and soils on the prediction of cumulus convective rainfall; Rev. Geophys. 39 151-177.

Prasanna V and Yasunari T 2009 Time-space characteristics of seasonal and interannual variations of atmospheric water balance over south Asia; J. Meteor. Soc. Japan 87 263-287.

Prasanna V and Yasunari T 2010 Simulated changes in the atmospheric water balance over south Asia in the eight IPCC AR4 coupled climate models; Theor. Appl. Climatol. 104 139-158, doi: 10.1007/s00704-010-0331-6.

Rasmusson E M 1967 Atmospheric water vapor transport and the water balance of north America: Part I. Characteristics of the water vapor flux field; Mon. Weather Rev. 95 403-426.

Rasmusson E M 1968 Atmospheric water vapor transport and the water balance of north America: Part II. Large scale water balance investigations; Mon. Weather Rev. 96 720-734.

Risi C, Bony S and Vimeux F 2008 Influence of convective processes on the isotopic composition of precipitation and water vapor in the tropics: 2. Physical interpretation of the amount effect; J. Geophys. Res. 113, doi: 10.1029/ 2008JD009943.

Risi C, Bony S, Vimeux F, Frankenberg C, Noone D and Worden J 2010 Understanding the Sahelian water budget through the isotopic composition of water vapor and precipitation; J. Geophys. Res. 115, doi: 10.1029/ 2010JD024690.

Singh P, Ramasastri K S and Kumar N 1995 Topographical influence on precipitation distribution in different ranges of western Himalayas; Nord. Hydrol. 26 259-284.

Thayyen R J and Gergan J T 2010 Role of glaciers in watershed hydrology: A preliminary study of a 'Himalayan Catchment'; The Cryosphere 4 115-128.

Trenberth K E and C J Guillemot 1999 Evaluation of the atmospheric moisture and hydrological cycle in the JRA25 reanalyses; Clim. Dyn. 14 213-231.

Trenberth K E, Fasullo J, Smith L 2005 Trends and variability in column integrated water vapor; Clim. Dyn. 24 $741-758$. 
Twafik A B and Steiner A L 2010 The role of soil ice in land atmosphere coupling over the United States: A soil moisture-precipitation winter feedback mechanism; J. Geophys. Res. 116, doi: 10.1029/2010JD014333.

Xu J, Yu S, Liu J, Haginoya S, Ishigooka Y, Kuwagata T, Hara M and Yasunari T 2009 The implication of heat and water balance changes in a lake basin on the Tibetan Plateau; Hydrol. Res. Lett. 3 1-5.

Yang D, Kane D L, Hinzman L D, Zhang X, Zhang T and Ye H 2002 Siberian Lena river hydrologic regime and recent change; J. Geophys. Res. 107, doi: 10.1029/ 2002JD002542.

Yasunari T 1976 Seasonal weather variations in Khumbu Himal; Seppyo 38 74-83.

Yatagai A, Arakawa O, Kamiguchi K and Kawamoto H 2009 A 44-year daily gridded precipitation dataset for Asia based on a dense network of rain gauges; SOLA 5 137-140.

Zhang J, Wu L and Dong W 2011 Land atmosphere coupling and summer climate variability over east Asia; J. Geophys. Res. 116, doi: 10.1029/2010JD014714. 